\title{
iPads in the classroom: teachers' perspectives post-implementation
}

\author{
Rob Miles \\ Higher Colleges of Technology, UAE
}

\begin{abstract}
This small-scale qualitative case study aimed to investigate English language teachers' perceptions of the impact of iPads in classrooms in ideal, actual and realistic terms. The study took place at the end of a five-year initiative that saw iPads introduced to English Language classrooms in a UAE Federal Institution. The investigation was carried out from a constructivist epistemology perspective using observations and interviews, analysed through the lens of the SAMR Model (Puentedura, 2010). While curriculum constraints limited the impact in this initiative, the device has the potential to engage students in collaborative tasks and assist in classroom management. A potential two-dimensional SAMR model is proposed, as are opportunities for further research.

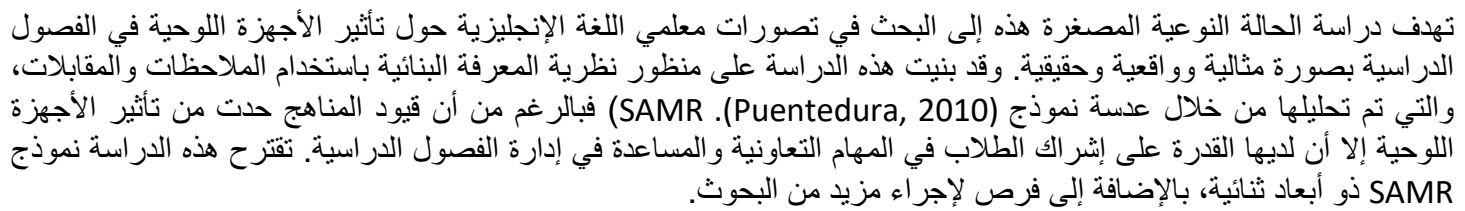

\section{Introduction}

The aim of this qualitative case study was to investigate how teachers perceived the impact of iPads in the English language classroom at the end of a five-year initiative, 2012-2017.

\section{Context}

In order to enter a degree programme, high school students in the United Arab Emirates (UAE) need to achieve an IELTS Band 5.0 or the equivalent score on a standardised national test of English proficiency. Those without the requisite score enter into a Foundations or Academic Bridge programme at one of the three Federal Institutions. They then have one academic year to achieve the required level and enter the programme of their choice.

In April 2012 the Ministry for Higher Education in the UAE mandated the introduction of iPads for all Foundations students and faculty in the three Federal Institutions. With the launch of over 14,000 iPads, this unique initiative was expected to transform education for post-secondary Emirati students.

However, classroom observations over the period of the initiative suggested that a significant transformation had not taken place. As the mandated use of iPads drew to a close in 2017, how had the mobile learning iPad initiative impacted Foundations English teachers and their classroom practice?

\section{Literature review}

In 2017 the iPad was still a fairly recent addition to the world of personal tablet computers. It was launched in April 2010, and its use in education was more recent in comparison to other devices such as laptops. While the literature on its usage in education settings has since grown, I identified four key papers at the time of the research that directly related to the iPad initiative in the UAE. 
In the first paper (Cavanaugh, Hargis, Munns, \& Kamali, 2013a), the authors carried out a descriptive analysis of session abstracts at a faculty professional development event that took place shortly before the nation-wide launch of iPads in the classroom. In this quantitative study, the Technological Pedagogical and Content model (TPCK) was applied as the analytical lens and no data on faculty perceptions was gathered. The authors coined the term 'iPadagogy', and went on to make the point that in order to sustain the initiative this new pedagogy needed to be supported by Challenge-Based and Inquiry-Based Learning and Assessment Objects. It was felt that the iPad would lead to greater student engagement and increased opportunities for collaboration. Most importantly for my study, they advocated the use of Puentedura's Substitution, Augmentation, Modification and Redefinition (SAMR) model (Puentedura, 2010) to measure the development of faculty engagement and the quality of teaching and learning.

The authors' second paper (Cavanaugh, Hargis, Kamali, \& Soto, 2013b) also took a quantitative approach, comparing abstracts from the first professional development event as a proxy measurement of TPCK with a second event, iCelebrate 2, six months later. This time they incorporated the SAMR model in order to measure the forward movement of iPads in the classroom. Although the authors discovered no significant difference between abstracts from the first and second events at Substitution and other levels (AMR), they felt that there was a practical shift, and given that any significant shift should not be expected for "at least one full year" (Puentedura, 2009, cited in Cavanaugh et al., 2013b, p.281) this was an important finding. From my perspective, the researchers' use of SAMR is significant, as is their recognition that

simple substitution of hardcopies for softcopies is inadequate to maximize the power of a mobile learning environment. (Cavanaugh et al., 2013b, p. 281)

A further study to come out of the initiative involved in part a case study within the framework of a Strengths, Weaknesses, Opportunities and Threats (SWOT) analysis to investigate faculty perceptions (Hargis, Cavanaugh, Kamali, \& Soto, 2014). In the case study, four faculty members were interviewed using 13 open-ended questions modified from Benton (2012). Various strengths, weaknesses and opportunities were identified, but only one major threat: 'This threat is the misalignment between assessments and teaching' (Hargis et al., 2014, p. 52).

One last paper to briefly mention here is A research agenda for the UAE iPad initiative (Gitsaki, Robby, Priest, Hamdan, \& Ben-Chabane, 2013). This paper looked at each of the three institutions as case studies; the point I take is the authors' conclusion that their case studies demonstrate the need for longitudinal research into mobile learning and how large-scale initiatives, such as iPads in classrooms, affect pedagogy and learning.

From a more global perspective, Nguyen, Barton and Nguyen (2015) point out that ' [c] urrent research is still at an early exploratory stage' (Nguyen, Barton, \& Nguyen, 2015, p. 191). Of twenty academic papers, all reporting on iPads in tertiary settings, only four were concerned with academics - teachers - only, with 12 focusing on students and four on both teachers and students. In one study, 50\% reported never using the iPad for teaching (Yeung \& Chung, 2011 in Nguyen et al., 2015), while in another study of 19 participants only 37\% used the iPad for teaching (Lindsey, 2011 in Nguyen et al., 2015). In fact, only two large-scale initiatives were reported, one of these being the UAE's as reported by Hargis et al. (2013). Once again, increased student engagement and opportunities for collaboration were mentioned (Nguyen et al., 2015, p. 195). The authors go on to say that

[n]o established teaching and learning practice was reported, which highlights the need for future large-scale and longitudinal studies. (Nguyen et al., 2015, p. 197)

A common theme mentioned in the literature discussed is improved student engagement and more opportunities for collaboration, through sharing work and challenge/inquiry based learning. While the iPad is relatively new, these concepts are not and connect to established theories of learning, teaching and second language acquisition. 
From a constructivist epistemology, Vygotsky sees social interaction - collaboration - as central to all learning (Vygotsky, 1978). Learning should be aimed at the Zone of Proximal Development (ZPD). This is the area just beyond what a learner can achieve. Teachers should use collaborative learning tasks that are ideally achieved with the help of a More Knowledgeable Other (MKO) who can assist or guide the learner. The MKO can be a teacher, or a more able peer. A student will achieve more through collaborative learning - in his/her ZPD with a MKO - than if they try to study alone. This is echoed in the concept of scaffolding, "whereby an adult or 'expert' helps somebody who is less adult or less expert" (Wood, Bruner, \& Ross, 1976, p. 89).

This connects to the concept of comprehensible input (Krashen, 1982) in second language acquisition. Learners achieve best when the input is comprehensible, just above their level. For Krashen, the answer lies not in "expensive equipment" (p. 1) but in using language for what it was designed for communication.

The articles focusing on the UAE initiative related directly to my research context, a "field ripe for research" (Gitsaki et al., 2013), while important points are also made about learning materials and assessment. The Systematic Literature Review (SLR) conducted in 2015 also supported the need for further investigation, and the suggested advantages of the iPad can be connected to established theories of learning and second language acquisition.

With the close of the initiative in 2017 this paper aimed to address a gap in the literature: a qualitative study of teachers' perceptions of the impact of the iPad. Recent literature has looked at the impact of iPads on mathematics teaching (Harrison \& Lee, 2018; Ozdemir, 2018) and on early childhood education (Hilton, 2018; Lu, Ottenbreit-Leftwich, Ding, \& Glazewski, 2017; Vaughan \& Beers, 2017), whereas this paper focuses on English language learning. The findings discussed in the following sections can contribute to the growing body of research on iPads in education.

\section{Theoretical framework}

As a theoretical framework, Puentedura's SAMR model (Puentedura, 2010\& 2012) provided the analytical lens for this research. As mentioned in the literature review, Hargis et al. (2013a) suggested that SAMR become the model to measure the impact of iPads, and indeed in a subsequent paper combined this with Mishra and Koehler's TPCK (2006) to measure the shift. Studies in contexts outside the UAE (Desjardins, van Oostveen, Muirhead, \& Goodman, 2011) and (Ifenthaler \& Schweinbenz, 2013) have combined SAMR with Jonassen et al.'s (2008) five principles of meaningful learning and the UTAUT model (Venkatesh et al., 2003) respectively. However, due to the limited scope of this study I solely be used the SAMR model (Figure 1). The model moves through four stages: Substitution, where the technology acts purely as a direct substitute with no functional change; Augmentation, with the technology still a direct substitute but with functional improvement; Modification, where the tool allows significant task redesign through to Redefinition, where the technology allows for the creation of new tasks that were previously inconceivable. The goal of the iPad initiative in the federal institutions in the UAE was the transformation of teaching and learning - modification and redefinition in SAMR terms. 

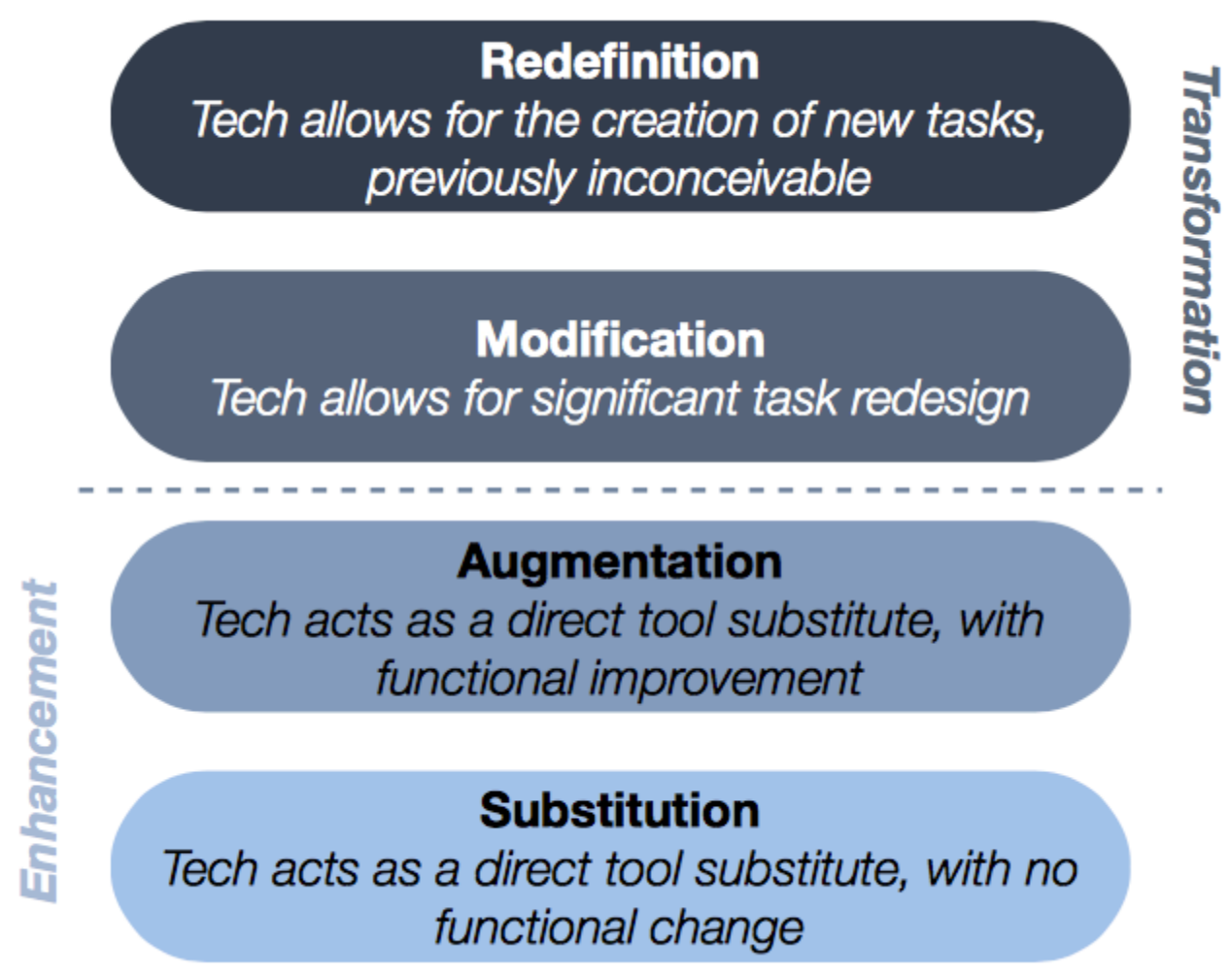

\section{Research questions}

RQ1: How is the impact of iPads on teaching practice perceived by English teachers?

$\mathrm{RQ2}$ : What do teachers perceive as the ideal pedagogical transformation iPads can bring about?

RQ3: What do teachers perceive as the actual pedagogical transformations iPads can cause?

RQ4: What do teachers perceive as realistic pedagogical changes?

\section{Methodology and methods}

A qualitative approach was taken, based on a constructivist epistemology where 'reality is a product of human intelligence interacting with experience in the real world' (Elkind, 2005, p. 334). Knowledge, in this case to answer research questions, is arrived at by means of the researcher's subjective observations in collaboration with the teachers' perceptions as expressed through interviews. The SAMR Model is employed as the analytical lens through which the data is viewed.

A case study approach was deployed. Of 20 campuses across the Federal Institutions, this study takes one campus as the bounded system, a 'unique example of real people in real situations' (Cohen, Manion, \& Morrison, 2013, p. 289). Teachers' attitudes and perceptions are central to the successful integration of technology in classrooms, and a qualitative case study using observations and interviews allows exploration of these areas. This combination of observation and interview allows for 'analytical rather than statistical generalisation' (Cohen et al., 2013, p. 294).

Before starting this project, ethical approval was sought and obtained from both the institution and Lancaster University, along with permission from the participants, who were free to withdraw at any stage. 
The first stage of data collection involved classroom observations. These took place between August 2016 and February 2017, and involved 18 teachers from a total of 21, with each observation totalling one 50-minute lesson period. The teachers also provided the observer with a lesson plan to help focus the observation. The data for this project consisted of field notes taken during the observation and did not include any summaries of the lesson or reflection from the teacher.

Each observation was broken down into learning activities - the number per lesson varied but in total I observed 85 distinct learning activities.

The next stage involved data analysis, for which I employed the SAMR Model. It was necessary to add an additional stage - zero - for learning activities that made no use of the iPad. Using this OSAMR coding system the observation data were arranged in Microsoft Excel in order to organise the 'data according to some theoretical scheme' (Silverman, 2013, p. 247) . I had concerns at this point - was I in fact quantifying the data by this classification? Was I moving towards pragmatism and mixed methods? However, '[q]uantification should not be seen as the enemy of good field research' (Silverman, 2013, p. 249), and the very act of classifying each learning activity was done both through the SAMR lens and my own lens as teacher, observer and researcher. Classifying and tabulating the data allowed me to direct the subsequent interviews in order to see if teachers' perceptions supported or challenged the observation data.

For the observations, five teachers were chosen as a typical sample. All five had: i) taught at the institution for at least one year prior to the launch of iPads in 2012; ii) participated in the initial training; iii) been involved in classroom teaching at the launch of the iPad; and iv) continued to teach in the Foundations programme throughout the 5-year period. The interviews were semi-structured although I had an interview protocol I allowed the interviews to flow and the interviewees to diverge from the questions as needed. The interviews were fairly short - around 30 minutes each - and were recorded on my laptop. Each participant signed a consent form, and also received a copy of the transcript for verification.

The interviews were transcribed using a normal word processing program and then analysed using the OSAMR model. Other categories then emerged - challenges, benefits and the future of the iPad in the classroom. I then attempted to tabulate key parts of each interview in order to match the data with the observations. My findings and the results in relation to the research questions are in the following sections.

\section{Findings}

Findings from the observations combined with the interviews are found below, with the results in terms of the actual research questions recorded in the following section.

\section{Challenges}

When technology is being used, one might fairly expect that technical difficulties will appear. However, across the observations, there were no instances of technical problems causing issues in the class. In interview, teachers reported initial technical issues at the launch of the iPad in 2012, centred around learning how to use it in a classroom context, but current technical issues related only to the age of the teachers' devices (Table 1 ).

Other challenges centred on classroom management and connected with T2's comment in the table above.

The iPad was found to be a distracting "smorgasbord of fun" (T4), while for another the iPad was "limiting" (T5) in the reading and writing process. 
Further to this, two teachers identified the difficulty of typing on an iPad as detrimental to productive tasks - especially writing, as students were unable to type properly on the touch screen.

Table 1: sample comments on challenges with iPads

\begin{tabular}{|c|c|c|}
\hline & 2012 & 2017 \\
\hline $\mathrm{T} 1$ & $\begin{array}{l}\text { I'd never used one before }[. . .] \text { the initial } \\
\text { problem was just how to go about using it }\end{array}$ & $\begin{array}{l}\text { It's old [...] the battery runs out really quickly } \\
{[\ldots] \text { it's very difficult to get through a session }}\end{array}$ \\
\hline $\mathrm{T} 2$ & $\begin{array}{l}\text {..it was taking something that was meant for } \\
\text { consumption and then making it a productive } \\
\text { education tool }\end{array}$ & $\begin{array}{l}\text { one of the limitations I have as a teacher }[. . .] \text { is } \\
\text { that we still have iPad 2's and 3's [...] one of } \\
\text { the things you can do with later iPads is } \\
\text { AirDrop [...] you'd still be able to have the } \\
\text { students share. }\end{array}$ \\
\hline
\end{tabular}

\section{Non-use}

Although no technical issues were observed, it was apparent that in many of the learning activities teachers were not employing the iPad at all. In fact, two complete lessons made no use of the device whatsoever. Both lessons were successful in their objectives - one had students produce a piece of writing, the other centred around vocabulary revision and practice - but were paper-based in their delivery.

Apart from these examples, there were several instances within lessons where teaching took place away from the iPad. Examples included physical hand-outs of reading texts with questions, spelling quizzes administered on paper and other paper-based classroom exercises for vocabulary, grammar and language skills. Overall, 25 activities observed (just under 30\%) did not use the iPad.

A similar trend emerged from the interviews. For example,

T5: In the beginning, I tried to follow what the upper management was saying [...] that we should go paperless and a hundred per cent iPad, which I found impossible. Eventually I've been using it as a resource. The information comes through the iPad, but everything the students do they do on paper and a notebook.

Furthermore, two teachers avoided using the iPad for reading lessons, preferring to use paper (T3 and T5).

At the same time, teachers also reported a drop if not complete reduction in paper:

T1: ...it did make the room much more paperless.

While another expects that no iPads in the class would have the following effect:

T4: Well, it would immediately mean much more paper.

It would seem that while the classroom is by no means paperless, to varying degrees the amount of paper has been reduced considerably. Furthermore, teachers are not using the iPad because they do not know how; rather that they are choosing not to use it if they think paper is a more suitable approach for a particular task or lesson.

\section{Substitution}

The first level of the SAMR Model, Substitution, also proved common in observation, with 15 learning activities (18\%) falling into this category. Examples consisted almost entirely of students accessing Portable Document Format (PDF) documents via the Learning Management System, and working on these in the same manner as a paper hand-out. Interviews supported the observations. For example, when asked about using iPads on a daily basis, interviewees replied:

T1: Probably not a lot different than you might do from the front of the room [...] they've got PDFs open to follow through... 
T4: Well, you'd do everything you normally did. [...] You could have it through an app [...] or deliver it in the form really of just a worksheet through the [learning management system].

The only difference is that rather than a physical hand-out, students have a document on their iPad.

\section{Augmentation}

The second level of the SAMR Model was in fact almost as common as zero usage. Twenty-four activities (28\%) used the iPad to augment, or enhance, a learning activity. Examples of Augmentation included using a dictionary app for vocabulary practice, taking interactive quizzes through applications like Nearpod or Quizlet - note here, however, that the teacher retained control of the activity. Students submitted their answers but had to wait for the teacher to tell them the actual answer. The interface for answering was enhanced, but the process for taking the quiz remained fairly traditional and teacher-centred. There is some support for these observations in the interviews:

T3: I would have something on paper for them to read, and maybe do an iPad activity like a Book Widget or a Kahoot.

In this case, the traditional use of a text on paper is augmented with an interactive activity on the students' devices.

In these first two levels of SAMR the teacher's role remained fairly central to the learning process.

\section{Modification}

Encouragingly, examples of Modification occurred almost as frequently as Substitution, with a total of 14 learning activities (16\%). Here we start to see the teacher taking a less central role and more independence to students. For example, students were accessing videos through the iPad as opposed to the teacher playing them at the front of the class. Online and interactive quizzes gave instant feedback, and elements of gamification became evident with services such as Kahoot! bringing competition to the classroom.

The use of interactive online quizzes to check understanding was frequently mentioned in the interviews:

T1: a PDF where they can link to some kind of an online quiz [...] again you could do some reinforcement with Kahoot and things like that.

T2: Well, start off with something like a Kahoot to practice vocabulary.

Another example to mention from the observations would be the use of discussion boards. Rather than simply being somewhere students store writing, these were used to provide audience as students commented and responded to each other's posts.

\section{Redefinition}

Here we should see technology redefining the learning task into an activity that would be impossible without the device, in this case an iPad. Although only seven instances were observed (8\%), they demonstrated real innovation in the classroom. For example, students used their iPads to take pictures that they then transformed into digital stories using an app (Educreations) that were then shared with their peers for feedback and further discussion. In another class, students accessed questions through a virtual reality app that turned pictures into multimedia (video and audio). They then answered these questions on an online quiz that showed their progress against other teams. Both were highly engaging activities that demonstrated the potential of the device. The interviewees also mentioned similarly creative examples, both examples below based on story telling:

T2: Things like Educreations or Vocaroo or Shadow Puppet [...] where they can take pictures and add in text and narrate and then they can share their work. 
T3: Something that my students liked was creating a story [...] Storymaker. Students can write an actual story, a digital story [...]] so they have graphics [...] and they can actually record their own voices.

It is important to note that with modification and redefinition the student has far more control of the outcome, with the teacher becoming more of a facilitator. There is also the opportunity for students to share and comment on the work of their peers, peers who become their audience.

So why is relatively little redefinition taking place? Teachers identify two main reasons: time/curriculum constraints, and learner constraints.

Table 2: Sample comments on time, curriculum and learner limitations

\begin{tabular}{|l|l|l|}
\hline \multirow{1}{*}{$\begin{array}{l}\text { Time and Curriculum } \\
\text { Constraints }\end{array}$} & T2 & $\begin{array}{l}\text { Well, time constraints is a big thing...you only have sat } 4 \text { hours with } \\
\text { a group...and you've got a quiz coming up at the end of the } \\
\text { week...focussing on the core takes precedence }\end{array}$ \\
\cline { 2 - 3 } & T3 & $\begin{array}{l}\text { I'm teaching Level 4, it's more IELTS focussed. I don't have time } \\
\text { You're labouring through the more core materials [for the } \\
\text { exam]...we are working towards a very rigid end result...therefore } \\
\text { the iPad's a massive distraction to that. }\end{array}$ \\
\hline \multirow{2}{*}{ Learner Constraints } & T5 & $\begin{array}{l}\text { The curriculum right now is reading, writing and listening, so I think } \\
\text { that hasn't allowed me to use it as much as I could. }\end{array}$ \\
\cline { 2 - 3 } & T2 & $\begin{array}{l}\text { Educreations? What put an end to that was the repetitiveness of it, } \\
\text { they really do lose a bit of interest. }\end{array}$ \\
\cline { 2 - 3 } & $\begin{array}{l}\text { There's this Kahoot fatigue because everyone was using it and the } \\
\text { novelty had worn off. }\end{array}$ \\
\hline
\end{tabular}

\section{Benefits}

While limited by time, curriculum and the learners themselves, those interviewed also identified several positives of iPads in the classroom. When used properly, the iPad was an engaging tool where "the delivery through PDF has been the real winner for me" (T1). Other teachers also mentioned that the iPad "removed the cord" (T2) tying them to the front of the class, allowing the teacher mobility in the classroom. Although limited by the final exam, teachers also felt that iPads brought an element of fun and allowed students to create things to use with their own peers.

In other words, the iPad can be an engaging, fun, motivating classroom tool that also disentangles the teacher from the front of the classroom.

\section{The future}

From the next academic year, students will bring laptops to college rather than iPads. As this paper is focussed on iPads, I shall only give a brief reference to teachers' observations on this change. While iPads, like Smartphones, are relatively intuitive to use, one teacher mentioned that when using laptops students are essentially 'Microsoft illiterate' (T1). Tasks involving documents, for example, take longer than expected. At the same time, the majority of those interviewed are not concerned about a future without iPads in the classroom. The future, it seems, is no longer device specific.

\section{Summary of findings}

In terms of the research questions, the following answers can be formulated from the interviews with the teachers, supported by the observations.

\section{RQ1: How is the impact of iPads on teaching practice perceived by English teachers?}


Teachers perceive the iPad primarily as a tool that students use to access materials via a Learning Management System or connect with web content. The device has the potential not only to engage but also to distract students. It allows for creativity and mobility, the latter particularly for the teacher, and assists in classroom management. However, the iPad is not the be all and end all.

\section{RQ2: What do teachers perceive as the ideal pedagogical transformation iPads can bring about?}

Ideally, the iPad is a tool that allows students to access and produce work with greater autonomy, moving towards learner independence. Work can be produced in collaboration with peers, and then shared with a wider audience. It is a multipurpose device that can connect with the Internet, act as a source of information and also a portal for production. When used to its full potential, it is an engaging classroom tool.

\section{RQ3: What do teachers perceive as the actual pedagogical transformations iPads can cause?}

In the language classroom, the iPad is not suitable for writing, a particular drawback for language learners. Longer readings are also felt to be less accessible when delivered via the iPad. Class management is facilitated by the mobility the teacher has - no longer are they tied to their computer at the front of the class. However, the ready access to games and the Internet can be a major distraction for students. The iPad need not be used $100 \%$ of the time, and the task needs to be suitable.

RQ4: What do teachers perceive as the realistic pedagogical changes?

In the context of this case study, in combination with learner constraints the major issues are the curriculum and the rigid assessments that teachers are working towards. They feel that given the amount they have to cover, with the focus on ultimately the IELTS examination, a paper-based test, they are unable to fully exploit the potential of the device. Using the iPad in this sense becomes a work around - How can I make it do what I need to do? rather than How can it make a real pedagogical difference to the classroom?

\section{Discussion}

Writing in 2014, Hargis et al. identified only one major threat to the successful use of iPads in the classroom: "the misalignment between assessments and teaching" (Hargis et al., 2014, p. 52). My research would tend to support this - the teachers identify that one of the major issues stopping them fully exploiting the potential of the device is the curriculum and its focus ultimately on the IELTS examation, a paper-based English proficiency test. Another point of interest to mention is the relatively low use of apps. There are a multitude of available apps listed on the App Store under Education - too many to count - and the first iCelebrate event in 2012 saw $80 \%$ of 51 abstracts focus solely on apps in the classroom (Cavanaugh et al., 2013a, p. 7). In the observations, however, only eight apps were used, while only six were mentioned as being used in the interviews. One, Kahoot!, is in fact a web-based game platform rather than an app. In both observations and interviews, the most prevalent app was the PDF delivered via a Learning Management System, Blackboard Learn in this case.

It is perhaps unfair to identify the other major constraints, the first being time and curriculum, as 'learner contraints'. Perhaps it would be fairer to identify this as an issue with affective filters (Krashen, 1982). Overuse of a popular application leads to a raising of the affective filter, and disengagement from the learning process. Or are we actually seeing ' learner contraints', issues with student engagement and motivation?

A further observation from the results is that the SAMR Model is too one-dimensional. From both the observations and the interviews, it becomes apparent that the iPads are being used in three main ways. Firstly, they are a device through which students access materials and information. Secondly, 
they are a device used to check understanding, primarily through online quizzes whether apps or webbased platforms. Thirdly, the device is used to produce content, either as writing or other types of media such as audio and video that can ultimately be shared with peers and a wider audience. I would therefore propose a two-dimensional model, combining SAMR with these three uses, Access, Check and Produce. I illustrate this in Table 3 below.

Table 3: Proposed 2D SAMR Model

\begin{tabular}{|c|c|c|c|}
\hline & Access & Check & Produce \\
\hline Substitution & $\begin{array}{l}\text { Students use the } \\
\text { device to access } \\
\text { documents. Control } \\
\text { lies with the teacher. }\end{array}$ & $\begin{array}{l}\text { Students use the } \\
\text { device to annotate } \\
\text { questions on a } \\
\text { document. Control lies } \\
\text { with the teacher. }\end{array}$ & $\begin{array}{l}\text { Students use the } \\
\text { device to write on a } \\
\text { document or create } \\
\text { new documents. } \\
\text { Teacher is generally } \\
\text { sole audience. }\end{array}$ \\
\hline Augmentation & $\begin{array}{l}\text { Students use the } \\
\text { device to access } \\
\text { materials in eTexts or } \\
\text { online, e.g. reading } \\
\text { passages. Control lies } \\
\text { with the teacher. }\end{array}$ & $\begin{array}{l}\text { Students use the } \\
\text { device to complete } \\
\text { interactive quizzes, but } \\
\text { control still lies with } \\
\text { the teacher. Little or } \\
\text { no gamification. }\end{array}$ & $\begin{array}{l}\text { Students use the } \\
\text { device to produce } \\
\text { writing in an } \\
\text { eTextbook. Teacher is } \\
\text { generally sole } \\
\text { audience. }\end{array}$ \\
\hline Modification & $\begin{array}{l}\text { Students use the } \\
\text { device to access videos } \\
\text { or less traditional eText } \\
\text { and online activities } \\
\text { such as jigsaws or } \\
\text { games. Control lies } \\
\text { with the student. }\end{array}$ & $\begin{array}{l}\text { Students use the } \\
\text { device to complete } \\
\text { interactive quizzes; } \\
\text { control lies with the } \\
\text { student and results are } \\
\text { in real-time. Elements } \\
\text { of gamification. }\end{array}$ & $\begin{array}{l}\text { Students use the } \\
\text { device to produce } \\
\text { writing that is shared } \\
\text { online to involve } \\
\text { audience. }\end{array}$ \\
\hline Redefinition & $\begin{array}{l}\text { Students use the } \\
\text { device combined with } \\
\text { VR to access video, text } \\
\text { and other media. } \\
\text { Control lies with the } \\
\text { student. }\end{array}$ & $\begin{array}{l}\text { Students use the } \\
\text { device to access } \\
\text { interactive quizzes in } \\
\text { combination with } \\
\text { other media e.g. VR, } \\
\text { video. Control lies with } \\
\text { the student. } \\
\text { Gamification occurs. }\end{array}$ & $\begin{array}{l}\text { Students use the } \\
\text { device to produce } \\
\text { digital stories, } \\
\text { dialogues, videos and } \\
\text { other media that can } \\
\text { be shared with a wider } \\
\text { audience. }\end{array}$ \\
\hline
\end{tabular}

While very much a prototype, this 2D SAMR Model shows that the device can be employed at each of the SAMR stages with any of the three identified uses. For example, a student could access a PDF via the Learning Management System (Substitution). They could then check their understanding through a quiz such as Kahoot, working collaboratively in teams or alone, and get their results in real-time (Modification). Finally, they could then use an app like Educreations to make a digital story displaying what they have learnt, sharing it with peers for feedback (Redefinition). In another lesson, all three uses could occur at one SAMR level. The SAMR Levels could be moved through horizontally, diagonally or vertically, as illustrated in Table 4. 
Table 4: moving through SAMR in 2D.

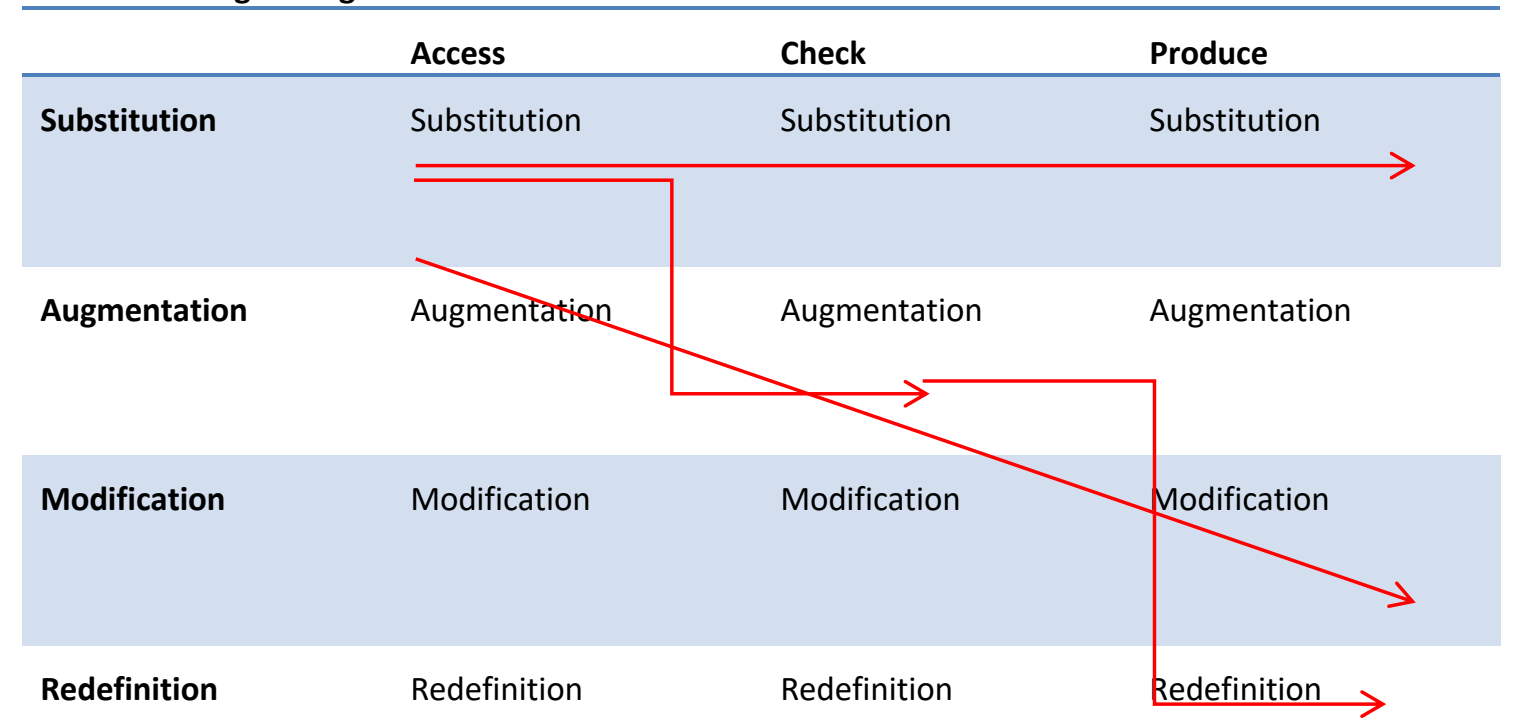

Another point to draw from this is that as the device usage moves from Substitution to Redefinition, the control moves from the traditional, teacher-centred approach to greater independence and student autonomy. Although only seen rarely in my observations and interviews, the fact that it has occurred despite limitations of curriculum proves that it is possible and perhaps desireable, given the right context. I illustrate this in Figure 2.

Figure 2: SAMR - from teacher dependence to learner independence

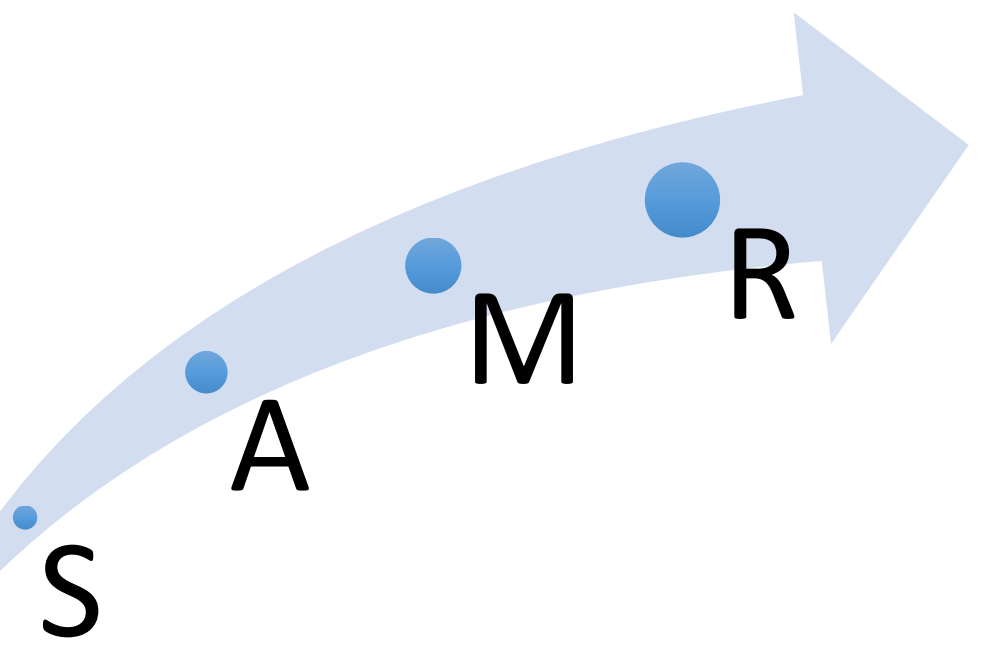

Teacher-centred

Student autonomy

Obviously, this extended 2D SAMR Model will need to be tested in further research.

Although the iPad has not had the major transformative effects hoped for at the outset of the initiative, and has not led to a new pedagogy in the context of this case study, there are many positives to take from the project. Redefinition is possible, and students can be engaged in creative ways to take responsibility for their own learning when the conditions allow. Furthermore, we are far from the mere 37\% of teachers using the iPad in Lindsey's 2011 study (Nguyen et al., 2015). The iPad initiative 
has led to, in this case study at least, a core of digitally literate teachers who are able to employ the device effectively - when appropriate - within the limits of curriculum, time and learner.

\section{Conclusion}

The study has a number of limitations. Firstly, the observations provided only a snapshot of teaching practice. A longitudinal approach would likely yield valuable data; staying with one class for one teaching week, for example, might prove more useful. Follow-up interviews would also prove important if time allowed, with more focus on actual teaching practice of different language skills and functions. In general, the study would have benefitted from a longitudinal increase and broadening of interview data. The very nature of a case study means that its scope is limited, however.

There are also several opportunities for further studies. Besides the 2D SAMR Model proposed earlier, it would be relevant to look at how the iPad supports scaffolding, focusing on the Zone of Proximal Development and how the iPad works on, or even as, the More Knowledgeable Other (Vygotsky, 1978). From a second-language acquisition perspective, how does the iPad assist in lowering the affective filter, thereby facilitating language learning (Krashen, 1982)? I would also be interested in investigating affordances, uses, outcomes and impacts (Passey, 2013), especially given that students moved to laptops in the following academic year. It would also be interesting to look into why some teachers are in fact using paper rather than iPads. Are there pedagogical reasons behind this choice or is it due to classroom management issues? This would also tie in with researching student motivation and engagement, the learner constraints mentioned previously.

In conclusion, although neither longitudinal nor large scale, I believe this paper can make a contribution to the body of literature. Students on the Foundations programme, at least at one of the three Federal institutions, ceased using iPads in class in 2017 and moved to laptops instead. This case study provides some insight into teachers' perspectives of the impact of iPads at the end of the project and makes, I hope, a small contribution to the growing body of literature on iPads in the classroom.

\section{Acknowledgements}

This research was undertaken as part of the PhD in E-research and Technology Enhanced Learning in the Department of Educational Research at Lancaster University. I am pleased to acknowledge the contribution of tutors and peers in supporting the development of this study and its report as an assignment paper.

\section{References}

Cavanaugh, C., Hargis, J., Kamali, T., \& Soto, M. (2013b). Substitution to augmentation: Faculty adoption of iPad mobile learning in higher education. Interactive Technology and Smart Education, 10(4), 270-284.

Cavanaugh, C., Hargis, J., Munns, S., \& Kamali, T. (2013a). iCelebrate teaching and learning: Sharing the iPad experience. Journal of teaching and learning with technology, 1(2), 1-12.

Cohen, L., Manion, L., \& Morrison, K. (2013). Research Methods in Education: Taylor and Francis.

Desjardins, F., van Oostveen, R., Muirhead, W., \& Goodman, W. M. (2011). Tablet PCs and reconceptualizing learning with technology: a case study in higher education. Interactive Technology and Smart Education, 8(2), 78-93.

Elkind, D. (2005). Response to objectivism and education. Paper presented at the The Educational Forum. 
Gitsaki, C., Robby, M. A., Priest, T., Hamdan, K., \& Ben-Chabane, Y. (2013). A research agenda for the UAE iPad initiative. Learning and teaching in higher education: Gulf perspectives, 10(2).

Hargis, J., Cavanaugh, C., Kamali, T., \& Soto, M. (2014). A federal higher education iPad mobile learning initiative: triangulation of data to determine early effectiveness. Innovative Higher Education, 39(1), 45-57.

Harrison, T. R., \& Lee, H. S. (2018). iPads in the mathematics classroom: Developing criteria for selecting appropriate learning apps. International Journal of Education in Mathematics, Science and Technology, 6(2), 155-172.

Hilton, A. (2018). Engaging Primary School Students in Mathematics: Can iPads Make a Difference? International Journal of Science and Mathematics Education, 16(1), 145-165.

Ifenthaler, D., \& Schweinbenz, V. (2013). The acceptance of Tablet-PCs in classroom instruction: The teachers' perspectives. Computers in Human Behavior, 29(3), 525-534.

Krashen, S. (1982). Principles and practice in second language acquisition.

Lu, Y.-H., Ottenbreit-Leftwich, A. T., Ding, A.-C., \& Glazewski, K. (2017). Experienced iPad-using early childhood teachers: Practices in the one-to-one iPad classroom. Computers in the Schools, 34(1-2), 923.

Nguyen, L., Barton, S. M., \& Nguyen, L. T. (2015). Ipads in higher education-hype and hope. British Journal of Educational Technology, 46(1), 190-203.

Ozdemir, M. (2018). Practices and attitudes of students and teachers using iPads in high school mathematics classes Student Engagement and Participation: Concepts, Methodologies, Tools, and Applications (pp. 1162-1177): IGI Global.

Passey, D. (2013). Inclusive Technology Enhanced Learning: Taylor \& Francis.

Puentedura, R. (2010). SAMR and TPCK: intro to advanced practice. Retrieved from http://hippasus.com/resources/sweden2010/SAMR_TPCK_IntroToAdvancedPractice.pdf

Puentedura, R. $(2012,2012)$. The SAMR Model: Background and Exemplars. Retrieved from http://www.hippasus.com/rrpweblog/archives/2012/08/23/SAMR_BackgroundExemplars.pdf

Silverman, D. (2013). Doing qualitative research (Fourth edition ed.).

Vaughan, M., \& Beers, C. (2017). Using an exploratory professional development initiative to introduce iPads in the early childhood education classroom. Early Childhood Education Journal, 45(3), 321-331.

Vygotsky, L. S. (1978). Mind in society: The development of higher psychological processes: Harvard university press.

Wood, D., Bruner, J. S., \& Ross, G. (1976). The role of tutoring in problem solving. Journal of child psychology and psychiatry, 17(2), 89-100. 